\title{
Effect of sintering temperature on phase-formation behavior and mechanical properties of silica ceramics prepared from rice husk ash
}

\author{
J.P. Nayak and J. Bera* \\ Department of Ceramic Engineering, National Institute of Technology, Rourkela 769008, \\ Orissa, India
}

(Received 9 August 2009; final version received 9 November 2009)

\begin{abstract}
Silica ceramics were prepared using three types of raw materials derived from rice husk. Cleaned husk and acid-leached husk were burned at $700^{\circ} \mathrm{C}$ to get brown ash (BA) and white ash, respectively. The third type was silica gel (SG) derived from BA through the alkaline extraction of silica from ash followed by acid neutralization. Granulated powders were pressed and pellets were sintered at $700-1400^{\circ} \mathrm{C}$ range. Phase-formation behavior, densification characteristics, and mechanical strength of ceramics were investigated and correlated with microstructural features. Ceramics made of SG showed the highest density and mechanical strength among all. All the ceramics were initially amorphous and transformed into crystalline silica above a specific sintering temperature. Microstructure shows the formation of cracks in the ceramics when they contain cristobalite phases. Amorphous-to-crystalline phase transformation temperature in different types of silica source was dependent on the amount of impurity and residual hydroxyl group content.
\end{abstract}

Keywords: silica; amorphous materials; crystallization temperature; phase transformations; mechanical properties

\section{Introduction}

Rice husk ash (RHA) is a waste material generated by the energy-producing plant which uses rice husk as a fuel [1]. Disposal of this waste material poses a problem due to the environmental dust pollution. Efficient utilization of the ash is a challenge for different rice-producing countries, because the rice mill generally uses husk as a fuel for its own energy generation. Many attempts have been made to utilize RHA, for example, to prepare cordierite ceramics [2,3], whiteware ceramics [4], zeolite [5,6], as a filler material in cement and rubber [7,8], etc. RHA mainly contains amorphous silica (90-98 wt\%). This amorphous silica source has been successfully utilized to prepare different siliconbased compounds like silicon carbide [9,10], silicon nitride [11], solar grade silicon [12], high-purity silica-based material like silica gel (SG) [13], silica aerogel [14,15], etc.

Silica is a highly refractory material and is used for the manufacturing of refractory bricks. Kapur [16] has reported the preparation of a silica-based insulator utilizing RHA as a raw material. One of the important properties of a refractory is the mechanical property. Silica exists in three main polymorphic forms: quartz, tridymite, and cristobalite.

*Corresponding author. Email: jbera@rediffmail.com 
Each form exists in two or more subforms. Transitions between forms, such as quartz to tridymite or tridymite to cristobalite, are reconstructive so that $\mathrm{Si}-\mathrm{O}$ bonds are broken with the rearrangement of $\mathrm{SiO}_{4}$ tetrahedral. Whereas, transitions within a form, such as $\alpha$ - to $\beta$-quartz or cristobalite, are displacive so that no atomic bonds are broken. Some of the displacive transformations are instantaneous and accompanied by large volume changes. Heating cycling through these inversions can have catastrophic effects on the mechanical properties of a body containing these phases. These volume changes produce cracks in the body leading to a decrease in mechanical strength. So, care should be taken during the production of a silica-based body.

Amorphous silica of RHA transforms into crystalline form upon heat treatment in the temperature range $900-1300^{\circ} \mathrm{C}$ depending on the impurities present in the ash [17]. The phase-transformation behavior and related mechanical strength in the RHA-based silica body have not been studied in detail. In this investigation, three different silica raw materials, which were derived from RHA, have been used to prepare silica-based ceramics. The specimens were sintered at different temperatures to see the effect of heat treatment on phase transformation, densification, and mechanical strength of the body.

\section{Experimental}

Rice husk, collected from a local rice mill, was washed thoroughly with water and dried. The dry husk was burned at $700^{\circ} \mathrm{C}$ for $6 \mathrm{~h}$ in air atmosphere to get the ash. The ash was brownish in color and termed brown ash (BA). To prepare more pure ash, the cleaned husk was acid leached with $3 \mathrm{~N} \mathrm{HCl}$ solutions under boiling condition for $1 \mathrm{~h}$ followed by thorough washing with warm water. Then the husk was dried at $100^{\circ} \mathrm{C}$ for $8 \mathrm{~h}$ and burned at $700^{\circ} \mathrm{C}$ for $6 \mathrm{~h}$ in air atmosphere. The ash thus obtained was whitish in color and designated as white ash (WA).

BA was used to synthesize SG raw material. Five grams of BA was added to $100 \mathrm{~mL}$ of $1 \mathrm{M} \mathrm{NaOH}$ solution and boiled for $1 \mathrm{~h}$ to extract silica from ash. The solution was filtered to separate the residue. The extracted sodium silicate solution was added dropwise to $1 \mathrm{~N} \mathrm{HCl}$ solution with constant stirring until the $\mathrm{pH}$ of the solution reached 6 . Within few minutes the solution turned into a gel. The gel was washed thoroughly with water to remove sodium chloride. The washed gel was dried to get SG.

All the precursors BA, WA, and SG were ground thoroughly in a pot mill individually for $24 \mathrm{~h}$ to get the powder. Particle size distributions of the powders were measured using Malvern Mastersizers Instruments. The chemical compositions of BA, WA, and SG powders were determined by X-ray fluorescence (Horiba MESA 500W). Powders were granulated by blending $1 \mathrm{wt} \%$ PVA. Pellets of $15 \mathrm{~mm}$ diameter and approximately $3.5 \mathrm{~mm}$ thickness were uniaxially pressed at 2.5 -ton pressure using granules. The pellets were heated at a rate of $2^{\circ} \mathrm{C} \mathrm{min}^{-1}$ until $600^{\circ} \mathrm{C}$ and held there for $60 \mathrm{~min}$ followed by heating at a rate of $3^{\circ} \mathrm{Cmin}^{-1}$ to different sintering temperatures. Sintering was carried out at temperatures ranging from 700 to $1400^{\circ} \mathrm{C}$ with a uniform holding time of $2 \mathrm{~h}$. The samples were then cooled naturally within the furnace.

The X-ray diffraction (XRD) patterns of the pellets were obtained using Philips PW 1830 (Holland) X-ray diffractometer. Rietveld analysis was performed on each of the diffraction patterns using the MAUD program. The program was developed to analyze diffraction spectra and obtain crystal structures, quantity, and microstructure of phases along with the texture and residual stresses. It applied the RITA/RISTA method as developed by Wenk et al. [18] and Ferrari and Lutterotti [19]. 
Infrared (IR) spectra of amorphous and crystalline silica specimens were obtained at a resolution of $2 \mathrm{~cm}^{-1}$, over the frequency range of $4000-400 \mathrm{~cm}^{-1}$, using Fourier transform infrared spectroscopy (FT-IR; Spectrum RX-1, Perkin Elmer). The spectra were taken from thin $\mathrm{KBr}$ pellets containing approximately $1 \mathrm{wt} \%$ samples. Pellets were prepared by compacting intimate powder mixture obtained by grinding $1 \mathrm{mg}$ of substance in $100 \mathrm{mg} \mathrm{KBr}$.

Bulk densities and water absorption of sintered pellets were determined. Mechanical strength of pellets was measured by compression test in an UTM (Hounsfield H10KT, UK) by "Brazilian Disc" methods with a crosshead speed of $0.5 \mathrm{~mm} \mathrm{~min}^{-1}$. Microstructures of pellets were observed under the scanning electron microscope (JSM-6480LV).

\section{Results and discussion}

\subsection{Powder characteristics}

Figure 1 shows the particle size distribution of BA, WA, and SG powders. Unimodal and narrow particle size distribution with an average particle size of 183 and $150 \mu \mathrm{m}$ were found for WA and BA powders, respectively. In the case of SG powder, a bimodal particle size distribution with average sizes of approximately 5 and $11 \mu \mathrm{m}$ was obtained.

The chemical analyses of powders are shown in Table 1 BA contains approximately $96 \% \mathrm{SiO}_{2}$ and the rest $4 \%$ are oxides of potassium, calcium, iron, zinc, and manganese. Except $\mathrm{SiO}_{2}$, all other oxides may be considered as impurities. SG, which was made from BA, contains $99.78 \%$ silica. The impurities were less in SG compared to BA because they were partially removed as residue during gel preparation. However, the acid leaching of the husk was more effective to remove these impurities as the WA contains nearly pure $\mathrm{SiO}_{2}(99.87 \%)$.

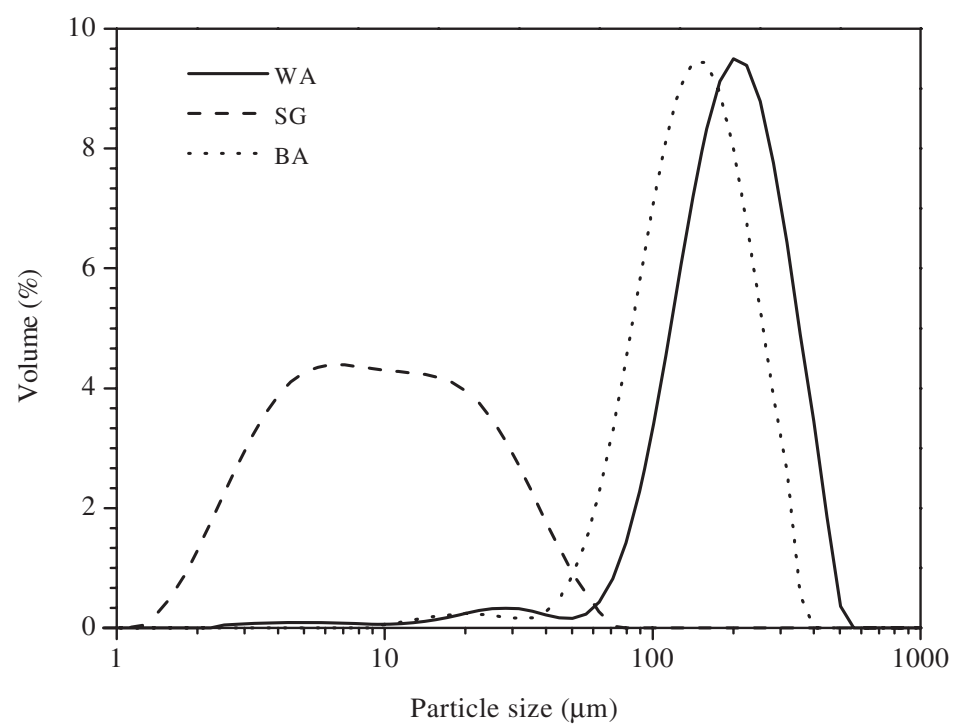

Figure 1. Particle size distribution of BA, WA, and SG powders. 


\subsection{Phase-formation behavior}

Figure 2 shows the XRD patterns of two BA specimens sintered at $900^{\circ} \mathrm{C}$ and $1000^{\circ} \mathrm{C}$. BA was amorphous up to $900^{\circ} \mathrm{C}$ and it transformed into crystalline silica at $1000^{\circ} \mathrm{C}$. Amorphous and crystalline XRD patterns of SG and WA were very similar to those shown in Figure 2. It was found that WA and SG transformed into crystalline phases from their amorphous states at $1300^{\circ} \mathrm{C}$ and $1200^{\circ} \mathrm{C}$, respectively. The crystalline phase was mainly cristobalite for all cases. Small amount of tridymite and/or quartz was also detected in them. The results indicate that crystallization temperature was different for different raw materials. The crystallization temperature in BA was the lowest among the three due to the presence of the highest amount of impurities $(\sim 4 \%)$ and residual hydroxyl group in it and that in WA was the highest among all due to its lowest impurity content $(\sim 0.13 \%)$. The presence of impurities and water vapor has been considered to play some role in the phase transformation of $\mathrm{SiO}_{2}$ [17]. It has been reported that the alkalis like $\mathrm{K}_{2} \mathrm{O}$ and $\mathrm{Na}_{2} \mathrm{O}$ in RHA accelerate the transformation of amorphous $\mathrm{SiO}_{2}$ to cristobalite or tridymite with

Table 1. Chemical analysis of raw materials (mass \%).

\begin{tabular}{lccc}
\hline Oxides & BA & SG & WA \\
\hline $\mathrm{SiO}_{2}$ & 96.01 & 99.79 & 99.87 \\
$\mathrm{~K}_{2} \mathrm{O}$ & 0.86 & - & - \\
$\mathrm{CaO}$ & 2.22 & 0.13 & - \\
$\mathrm{Fe}_{2} \mathrm{O}_{3}$ & 0.57 & 0.03 & 0.13 \\
$\mathrm{ZnO}$ & 0.06 & 0.05 & - \\
$\mathrm{Mn}_{2} \mathrm{O}_{3}$ & 0.28 & - & - \\
\hline
\end{tabular}

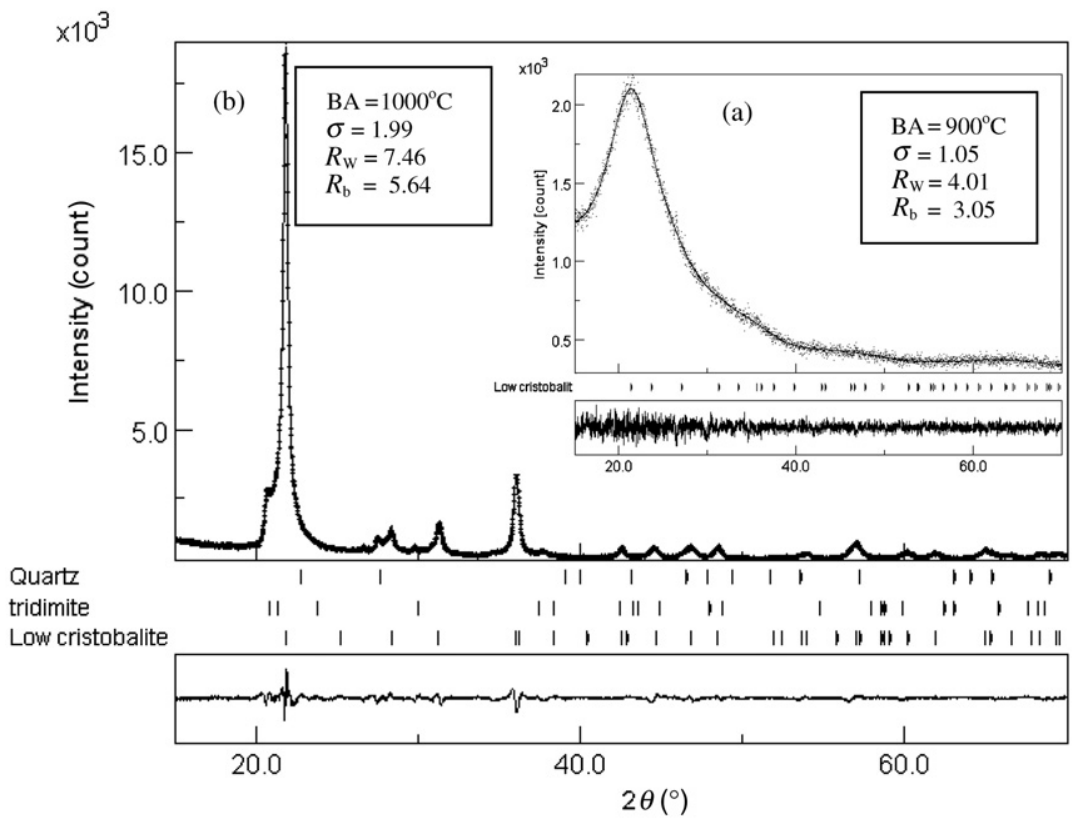

Figure 2. XRD patterns of BA sintered at (a) $900^{\circ} \mathrm{C}$ and (b) $1000^{\circ} \mathrm{C}$. 
a reduction in the transformation temperature from approximately $1200^{\circ} \mathrm{C}$ to $800^{\circ} \mathrm{C}$ even at low $(<1 \%)$ alkali contents [20].

It is well established that RHA constitutes of amorphous silica. To investigate the structural features of this amorphous material, Rietveld structure refinement was performed on each material. Figure 2 shows the typical Rietveld plots after final refinement for BA pellets sintered at $900^{\circ} \mathrm{C}$ and $1000^{\circ} \mathrm{C}$. Refinement $R$-factors and goodnessof-fit $(\sigma)$ are shown in the figure. For amorphous pattern refinement, silica glass (cubic, space group P2 3 ) and low cristobalite (tetragonal, space group $\mathrm{P} 4{ }_{1} 2_{1} 2$ ) were fitted in separate refinements. It was interesting to note that fitting with low cristobalite yielded lower $R$-factor and better $\sigma$ compared to silica glass. So, amorphous silica in the ash may be considered structurally more similar to low cristobalite. Many authors also proposed similar low cristobalite structure for amorphous silica in ash $[21,22]$.

For crystalline specimen of $\mathrm{BA}-1000^{\circ} \mathrm{C}$, a three-phase refinement was carried out considering low cristobalite $\left(\mathrm{P}_{1} 2_{1} 2\right)$, tridymite $\left(\mathrm{P}_{3} / \mathrm{mmc}\right)$, and low quartz (trigonal, $\mathrm{P} 2{ }_{3} 3_{4}$ ). Rietveld quantitative estimation shows about $62 \%$ low cristobalite, $30 \%$ tridymite, and $8 \%$ quartz. Since amorphous ash is more similar to low cristobalite, the formation of crystalline low cristobalite from amorphous material is justified. The material was heated at $1000^{\circ} \mathrm{C}$, which is the thermodynamic stability range for tridymite. For that reason, tridymite phase also crystallizes during heat treatment. The phase-transform anomaly in silica is a well-known phenomenon. Some amount of quartz also crystallizes may be due to this anomaly. Similar phase-formation behavior was also found in the case of SG and WA specimens.

FT-IR analysis was performed to study the crystallization behavior and nature of bound water in the silica specimen. Figure 3 shows the IR spectra of three specimens at their amorphous state and after crystallization by heat treatment. The broad band at $3410-3470 \mathrm{~cm}^{-1}$ is due to the stretching vibration of the $\mathrm{O}-\mathrm{H}$ bond from the silanol groups ( $\mathrm{Si}-\mathrm{OH})$ and the $\mathrm{HO}-\mathrm{H}$ vibration of adsorbed water molecules in all silica specimens. The small band at $1635 \mathrm{~cm}^{-1}$ is attributed to the bending $\mathrm{H}-\mathrm{OH}$ bond of adsorbed water molecules. These bands were present in sintered samples because the water molecules were unable to escape from the silica matrix [23]. The band at $1100 \mathrm{~cm}^{-1}$ is due to the $\mathrm{Si}-\mathrm{O}-\mathrm{Si}$ asymmetric stretching vibration, while the band at $800 \mathrm{~cm}^{-1}$ has been assigned to a network $\mathrm{Si}-\mathrm{O}-\mathrm{Si}$ symmetric bond stretching vibration [24]. The band at $477 \mathrm{~cm}^{-1}$ is associated with a network $\mathrm{O}-\mathrm{Si}-\mathrm{O}$ bond bending modes [25]. In the case of crystalline $\mathrm{SiO}_{2}$ $\left(\mathrm{BA}-1000^{\circ} \mathrm{C}, \mathrm{SG}-1200^{\circ} \mathrm{C}\right.$, and $\mathrm{WA}-1300^{\circ} \mathrm{C}$ ), the new band at $622 \mathrm{~cm}^{-1}$ is attributed to the polymerized structure of framework crystalline silicates [25,26]. This is described as structure-dependent $\mathrm{Si}-\mathrm{O}-\mathrm{Si}$ symmetrical stretching vibrations [26] and due to cristobalite phase. This characteristics band of cristobalite has also been reported by Ying et al. [27].

\subsection{Densification behavior}

Figure 4 shows the bulk density and water absorption of different sintered specimens. Bulk density of BA increases slowly up to $800^{\circ} \mathrm{C}$ followed by a rapid increase up to $1000^{\circ} \mathrm{C}$. Above $1000^{\circ} \mathrm{C}$, the densification rate was very slow and body shows approximately $20 \%$ water absorption. Densification rate of WA was slow up to $1000^{\circ} \mathrm{C}$ followed by an increased rate up to $1300^{\circ} \mathrm{C}$, with water absorption of approximately $1 \%$. However, the densification rate of SG was rapid in the range of $700-900^{\circ} \mathrm{C}$, moderate in the $900-1200^{\circ} \mathrm{C}$ range and slow above $1200^{\circ} \mathrm{C}$, with approximately $1 \%$ water absorption. 


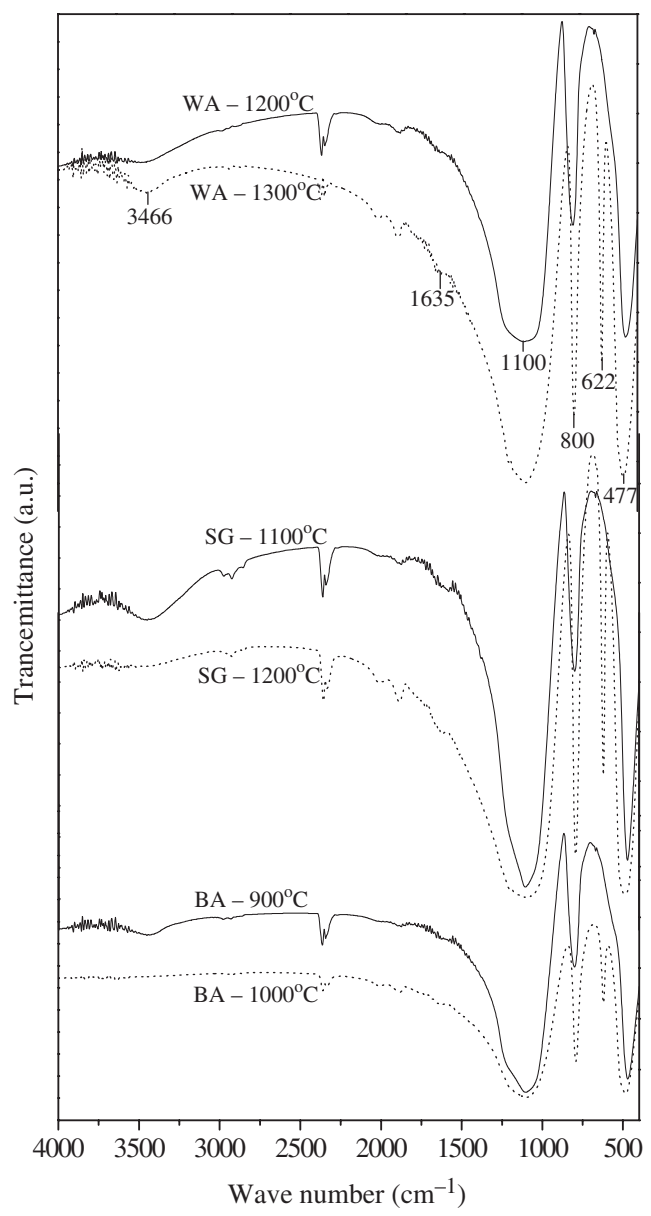

Figure 3. Representative FT-IR spectra of different silica specimens. Sintering temperature of each specimen is represented in its notation.

The most important driving force for sintering is the curvature of the particle surface. Finer the particles, higher will be the curvature and better will be the sinterability. SG has much finer particle size than the two ashes. For that reason, SG has the highest sinterability. However, the green density of SG was the lowest at approximately $0.87(0.01) \mathrm{gm} \mathrm{cc}^{-1}$ among all (WA $\sim 1.09(0.01)$, BA $\sim 1.19(0.02) \mathrm{gm} \mathrm{cc}^{-1}$ ). Finer particles are more prone to agglomeration, so the green density of $\mathrm{SG}$ is lower than others having coarser particles.

Initial slow densification of BA and WA may be due to the particle rearrangement. Intermediate increased densification of them, as well as the densification of SG, is due to the viscous flow of amorphous material into the pores. Sintering process in amorphous material refers to viscous sintering where matter transport occurs predominantly by viscous flow. Viscosity decreases with increasing sintering temperatures and it also decreases with increasing impurities. For this reason, densification increased with increasing sintering temperature. Intermediate rapid densification stage of BA started from $800^{\circ} \mathrm{C}$ compared to that of WA at $1000^{\circ} \mathrm{C}$. The possible reason may be the decreased 


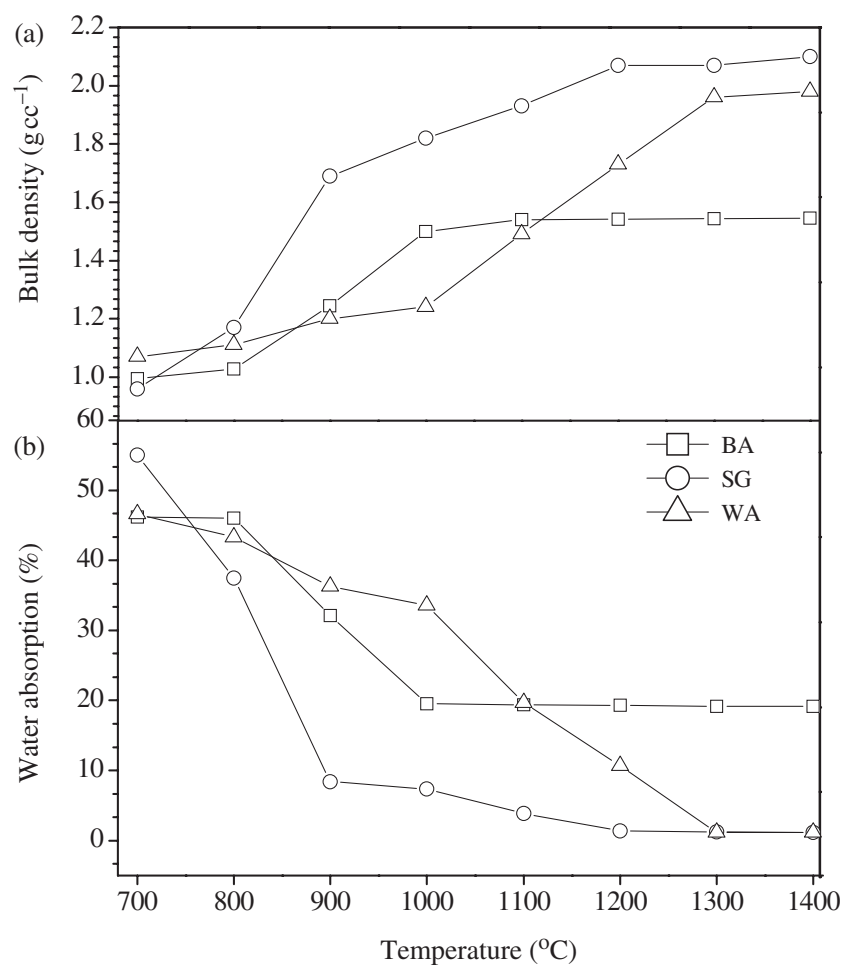

Figure 4. Variation of (a) bulk density and (b) water absorption of specimen with sintering temperature.

viscosity of BA as it contains nearly $4 \mathrm{wt} \%$ impurities. The initial increased densification of SG may be due to its decreased viscosity as the material is a gel. There was a marked change in the densification slope at $900^{\circ} \mathrm{C}$ in SG. This may be due to the differential densification behavior of bimodal particle size distribution in SG, where finer particles and associated small pores favor rapid sintering.

The final stage of densification where there was very slow increase in bulk density started from 1000,1200 , and $1300^{\circ} \mathrm{C}$ for $\mathrm{BA}, \mathrm{SG}$, and $\mathrm{WA}$, respectively. The rate of densification and pore removal was very slow in $\mathrm{BA}$ above $1000^{\circ} \mathrm{C}$ may be due to the transformation of amorphous materials into crystalline phase. The crystalline phase has considerably higher viscosity than amorphous phase and thus densification decreased. The density of BA was the lowest among all due to the early crystallization in the body. Densification of SG and WA were virtually stopped above 1200 and $1300^{\circ} \mathrm{C}$, respectively, due to the same crystallization phenomenon. These are the typical examples of viscous sintering with crystallization. The results conclude that the most favorable processing strategy for the materials is the achievement of full density prior to any significance crystallization.

\subsection{Mechanical properties}

Figure 5 shows the compressive strength of BA, WA, and SG with different sintering temperatures. The strength increases with sintering temperature, mainly due to the 
increase in bulk density in all the ceramics. However, there was an anomaly, that is, the fall in strength for each ceramic at a specific sintering temperature. These specific sintering temperatures were 1200,1300 , and $1400^{\circ} \mathrm{C}$ for $\mathrm{SG}$, WA, and $\mathrm{BA}$, respectively. To investigate the reason for this strength anomaly, the microstructural investigation was performed on sintered pellets. Figure 6 shows the surface microstructure of the three ceramics that were sintered at the specific temperature where anomaly takes place. All the ceramics show the continuous formation of crack.

For SG and WA ceramics, the anomaly temperatures were also their crystallization temperature, as described earlier. The crystalline phases were mainly cristobalite and the crack formation was due to the volume change associated with $\beta$ - to $\alpha$-cristobalite transition, which occurred in the temperature range of $200-270^{\circ} \mathrm{C}$ during the cooling of sintered specimens. The mechanical strength of these ceramics decreased due to this crack formation. After those temperatures, the strength increased to some extent mainly due to the increased densification with temperature.

Strength development behavior of BA ceramics shows some differences from the other two ceramics as shown in Figure 6(a). As described, the crystallization in BA takes

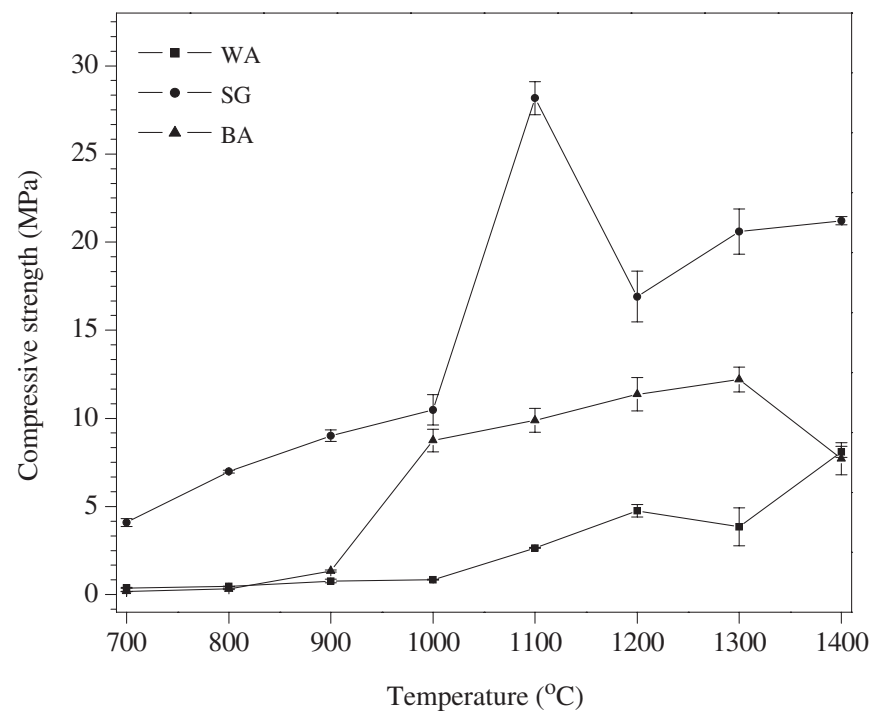

Figure 5. Variation of compressive strength with sintering temperature.
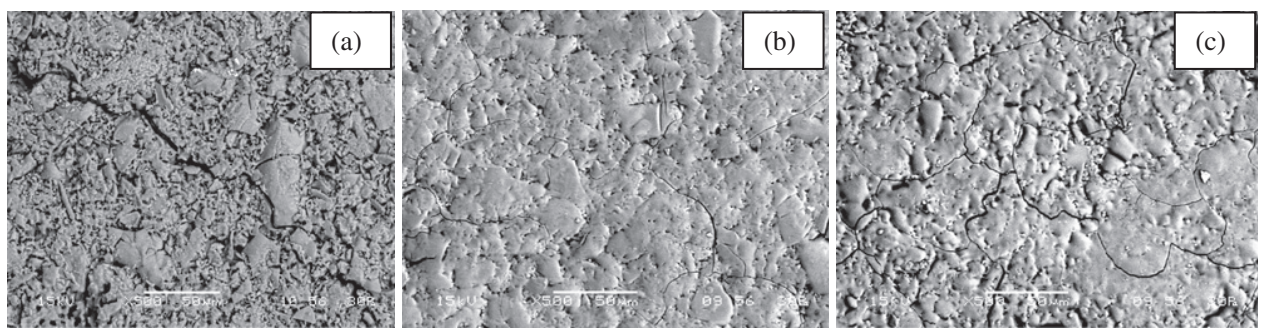

Figure 6. Surface microstructure of a pellet: (a) BA sintered at $1400^{\circ} \mathrm{C}$, (b) SG sintered at $1200^{\circ} \mathrm{C}$, and (c) WA sintered at $1300^{\circ} \mathrm{C}$. 
place at $1000^{\circ} \mathrm{C}$. However, the strength of the ceramics increased at that temperature, which phenomenon is contradictory to those occurred in SG and WA ceramics. At $1000^{\circ} \mathrm{C}$, the $\mathrm{BA}$ body contains a high volume percentage of water absorption of approximately $20 \%$. Highly porous structure may accommodate the volume change due to $\beta$ - to $\alpha$-cristobalite transformation. So the increased strength at $1000^{\circ} \mathrm{C}$ may be due to increased densification as there was approximately $14 \%$ decrease in water absorption compared with $900^{\circ} \mathrm{C}$ specimen. There was very slow strength development from $1000^{\circ} \mathrm{C}$ to $1300^{\circ} \mathrm{C}$ due to slow densification. The strength decreased at $1400^{\circ} \mathrm{C}$ may be due to the formation of increased amount of cristobalite and prominence of crack, as shown in Figure 6(c).

\section{Conclusion}

RHA silica-based ceramics were used to study the effect of sintering temperature on the phase formation of silica and mechanical properties of the ceramics. BA, obtained by burning husk, shows the presence of about $96 \mathrm{wt} \%$ amorphous $\mathrm{SiO}_{2}$ and the rest $4 \%$ impurities like $\mathrm{CaO}, \mathrm{Fe}_{2} \mathrm{O}_{3}, \mathrm{~K}_{2} \mathrm{O}, \mathrm{ZnO}$, and $\mathrm{Mn}_{2} \mathrm{O}_{3}$. WA, prepared by burning acid-leached husk, contains almost pure silica. SG powder was prepared from BA through the alkaline extraction of silica from ash followed by acid neutralization. Among the three powders, gel powder shows fine particle size in the $5-11 \mu \mathrm{m}$ range. During sintering, amorphous silica transformed mainly into cristobalite phase at $1000^{\circ} \mathrm{C}, 1200^{\circ} \mathrm{C}$, and $1300^{\circ} \mathrm{C}$, respectively, for $\mathrm{BA}, \mathrm{SG}$, and WA ceramics. The earliest phase transformation in BA was due to its high impurity and residual hydroxyl group content. Densification rate of all specimens decreased above crystallization temperature. An anomaly in increasing strength with sintering temperature was found, showing a fall in strength as and when amorphous silica transformed to cristobalite. Microstructural investigation revealed that the fall in strength was due to the crack formation by the high-low displacive phase transformation of cristobalite. Finally, it may be concluded that the three types of husk ash silica behaved differently with respect to amorphous-to-crystalline phase transformation due to their differences in impurity and residual hydroxyl group content.

\section{Acknowledgement}

The authors are thankful to the Ministry of Environment and Forests, Government of India, New Delhi, for providing the research grant vide sanction no. 19/50/2004 RE.

\section{References}

[1] U. Kalapathy, A. Proctor, and J. Shultz, An improved method for production of silica from rice hull ash, Bioresour. Technol. 73 (2000), pp. 257-262.

[2] M.K. Naskar and M. Chatterjee, A novel process for the synthesis of cordierite $\left(\mathrm{Mg}_{2} \mathrm{Al}_{4} \mathrm{Si}_{5} \mathrm{O}_{18}\right)$ powders from rice husk ash and other sources of silica and their comparative study, J. Eur. Ceram. Soc. 24 (2004), pp. 3499-3508.

[3] S. Kurama and H. Kurama, The reaction kinetics of rice husk based cordierite ceramics, Ceram. Int. 34 (2008), pp. 269-272.

[4] C.S. Prasada, K.N. Maiti, and R. Venugopal, Effect of substitution of quartz by rice husk ash and silica fume on the properties of whiteware compositions, Ceram. Int. 29 (2003), pp. 907-914. 
[5] H. Hamdan, M.N.M. Muhid, S. Endud, E. Listiorini, and Z. Ramli, 298i MAS NMR, XRD and FESEM studies of rice husk silica for the synthesis of zeolites, J. Non-Cryst. Solids 211 (1997), pp. 126-131.

[6] K. Kordatos, S. Gavela, A. Ntziouni, K.N. Pistiolas, A. Kyritsi, and V. Kasselouri-Rigopoulou, Synthesis of highly siliceous ZSM-5 zeolite using silica from rice husk ash, Microporous and Mesoporous Mater. 115 (2008), pp. 189-196.

[7] D.G. Nair, A. Fraaij, A.A.K. Klaassen, and A.P.M. Kentgens, A structural investigation relating to the pozzolanic activity of rice husk ashes, Cem. Concr. Res. 38 (2008), pp. 861-869.

[8] L. Sereda, M.M. Lopez-Gonzalez, L.L.Y. Visconte, R.C.R. Nunes, C.R.G. Furtado, and E. Riande, Influence of silica and black rice husk ash fillers on the diffusivity and solubility of gases in silicone rubbers, Polymer 44 (2003), pp. 3085-3093.

[9] J.N. Romero and F.R. Reinoso, Synthesis of SiC from rice husk catalyzed by iron, cobalt or nickel, J. Mater. Sci. 1 (1996), pp. 779-784.

[10] P. Gorthy and M.G. Pudukottah, Production of silicon carbide from rice husks, J. Am. Ceram. Soc. 82 (1999), pp. 1393-1400.

[11] I.A. Rahman, Preparation of $\mathrm{Si}_{3} \mathrm{~N}_{4}$ by corbothermal reduction of digested rice husk, Ceram. Int. 20 (1994), pp. 195-199.

[12] J.A. Amick, Purification of rice hulls as a source of solar grade silicon for solar cells, J. Electrochem. Soc. 129 (1982), pp. 864-866.

[13] V.P. Della, I. Kuhn, and D. Hotza, Rice husk ash as an alternate source for active silica production, Mater. Lett. 57 (2002), pp. 818-821.

[14] T. Li and T. Wang, Preparation of silica aerogel from rice hull ash by drying at atmospheric pressure, Mater. Chem. Phys. 112 (2008), pp. 398-401.

[15] A.S. Dorcheh and M.H. Abbasi, Silica aerogel: Synthesis, properties and characterization, J. Mater. Process. Technol. 199 (2008), pp. 10-26.

[16] P.C. Kapur, Thermal insulations from rice husk ash, an agricultural waste, Ceramurgia Int. 6 (1953), pp. 75-78.

[17] W.A. Deer, R.A. Howie, and J. Zussmaan, Rock Forming Minerals, Longmans, London, 1963.

[18] H.R. Wenk, S. Matthies, and L. Lutterotti, Texture analysis from diffraction spectra, Mater. Sci. Forum 157 (1994), pp. 473-480.

[19] M. Ferrari and L. Lutterotti, Method for the simultaneous determination of anisotropic residual stresses and texture by X-ray diffraction, J. Appl. Phys. 76 (1994), pp. 7246-7255.

[20] W. Panpa and S. Jinawath, Synthesis of ZSM-5 zeolite and silicalite from rice husk ash, Appl. Catal., B: Environ. 90 (2009), pp. 389-394.

[21] T.-H. Liou, Preparation and characterization of nano-structured silica from rice husk, Mater. Sci. Eng., A 364 (2004), pp. 313-323.

[22] S. Chandrasekhar, K.G. Satyanarayana, P.N. Pramada, P. Raghavan, and T.N. Gupta, Processing, properties and applications of reactive silica from rice husk - An overview, J. Mater. Sci. 38 (2003), pp. 3159-3168.

[23] F. Adam and J.-H. Chua, The adsorption of palmytic acid on rice husk ash chemically modified with Al(III) ion using the sol-gel technique, J. Colloid Interface Sci. 280 (2004), pp. 55-61.

[24] A. Bertoluzza, C. Fagnano, and M.A. Morelli, Raman and infrared spectra on silica gel evolving towards glass, J. Non-Cryst. Solids 48 (1982), pp. 117-128.

[25] K.S. Finnie, J.G. Thompson, and R.L. Withers, Phase transitions in cristobalite and related structures studied by variable temperature infra-red emission spectroscopy, J. Phys. Chem. Solids 55 (1994), pp. 23-29.

[26] I.P. Swainson, M.T. Dove, and D.C. Palmer, Infrared and Raman spectroscopy studies of the $\alpha-\beta$ phase transition in cristobalite, Phys. Chem. Miner. 30 (2003), pp. 353-365.

[27] J.Y. Ying and J.B. Benziger, Structural characterization of silica during sintering, Nanostruct. Mater. 1 (1992), pp. 149-154. 